\title{
Preparation and characterization of low cost flat ceramic membranes from easily available potters' clay for dye separation
}

\author{
JITU SAIKIA ${ }^{1,2}$, SUSMITA SARMAH ${ }^{1,2}$, JAYANTA J BORA $^{3}$, BIPUL DAS $^{4}$ \\ and RAJIB LOCHAN GOSWAMEE ${ }^{1,2, * \mathbb{D}}$ \\ ${ }^{1}$ Advanced Materials Group, Materials Science and Technology Division, CSIR-North East Institute of Science and \\ Technology, Jorhat, Assam 785006, India \\ ${ }^{2}$ Academy of Scientific and Innovative Research, Jorhat Campus, Jorhat 785006, India \\ ${ }^{3}$ General Engineering Group, Engineering Science and Technology Division, CSIR-North East Institute of Science and \\ Technology, Jorhat, Assam 785006, India \\ ${ }^{4}$ Chemical Engineering Group, Engineering Science and Technology Division, CSIR-North East Institute of Science and \\ Technology, Jorhat, Assam 785006, India \\ *Author for correspondence (goswamirl@ neist.res.in)
}

MS received 11 May 2018; accepted 12 September 2018; published online 4 April 2019

\begin{abstract}
In the present day scenario, the crisis of safe drinking water is an extremely serious issue across many parts of the globe and needs efficient methods to overcome this problem. The effort made in this study is to develop a method to prepare a ceramic membrane with locally available cheap compositions such as potters' clay, stone dust and tea waste materials for efficient adsorptive dye removal from water. The preparation of ceramic membrane was carried out by a paste pressing method and sintered at an optimized temperature of $900^{\circ} \mathrm{C}$ to obtain flat ceramic membranes of $42 \mathrm{~mm}$ in diameter and $3 \pm 0.5 \mathrm{~mm}$ thickness with good thermal and chemical stabilities with $52.51 \%$ porosity and average pore size of $0.49 \mu \mathrm{m}$. The membrane was capable of decolouring methylene blue and congo red from water with good efficiency and the used membrane was regenerated by calcining at $400^{\circ} \mathrm{C}$ for $30 \mathrm{~min}$ without much loss of its efficiency. Development of newer advanced products with the available local resources may be another way to sustain the small scale industry and livelihood of the people around.
\end{abstract}

Keywords. Potters' clay; ceramic membrane; characterization; decolourization; reusability.

\section{Introduction}

Ceramic filters and membranes have been extensively applied in a number of fields, such as food and beverage, biotechnology and pharmaceuticals, bulk and fine chemicals, waste recovery and recycling industries [1-4]. The ability of ceramic membranes to uniquely address the distinct need of frequent cleaning, high resistance to harsh operating environment and continuous flow conditions are some of their main advantages over other types of membranes or porous barriers [5]. In recent days, it is seen that tremendous attention is given towards membrane-based separation processes for application in different areas including water treatment, catalysis, industrial gas separation and many other biomedical applications [6-18]. Ceramic membranes can be regenerated for use over many cycles and can be applied to both aqueous and non-aqueous solution separations especially in petrochemical processing where organic membranes cannot be utilized [19].

Use of oxides of pure $\mathrm{Al}_{2} \mathrm{O}_{3}, \mathrm{TiO}_{2}, \mathrm{ZrO}_{2}, \mathrm{SiO}_{2}$ or their combinations for the preparation of ceramic membranes [5,10-26] with high chemical, mechanical and thermal stabilities are well established $[27,28]$ and are common, but the use of high cost inorganic precursors to obtain these oxides increases the cost as well as requires high sintering temperature $\left(>1100^{\circ} \mathrm{C}\right)$ for fabrication. The use of cheaper precursors such as ball clay, kaolin, quartz, feldspar, $\mathrm{CaCO}_{3}$, clay, sand and pyrophyllite for preparation of microfiltration range ceramic membranes have been reported $[29,30]$. Out of these, quartz, feldspar and pyrophyllite are expensive raw materials in comparison with widely available materials such as kaolin, ball clay and $\mathrm{CaCo}_{3}$. Apart from these common minerals, use of some location-specific natural minor minerals, such as natural apatite, Tunisian silty marls, local clay, Moroccan perlite, Spanish clay mixture, industrial waste coal fly ash, starch as porogen, natural Moroccan pozzolan and Moroccan clay [31-41] are also reported for fabrication of ceramic membranes. On a close investigation of the reported works, it is seen that a number of methods are available for ceramic membrane fabrication, but many of them lag in terms of cost efficacy and easy synthesizability. Preparation of reusable economic adsorbent materials for use in rural areas requires cheaper raw materials available near the place where the rural community resides. In such a context, we have tried to gainfully utilize potters' clay (PC) from a well-known locality 
in Assam, India which has been used from ancient times for earthenware pottery.

The rapid progress in the textile industry led to a high demand of dye molecules in the market [42,43], but the problem associated with it is the disposal of spent solutions $[44,45]$ containing a high amount of residual dye molecules. Casual disposal of it to natural water bodies leads to pollution. Although governments bring out different regulations and acts to control such matters, the problem is becoming chronic and the shortage of safe water further aggravates the matter. Due to their complex structure and synthetic origin by design, dye molecules are resistant to breakdown with time or on exposure to sunlight, enzymes, chemical oxidizing agents and water. Hence, they cannot be easily removed by conventional wastewater treatment processes $[46,47]$. Most of these dyes are highly toxic and can cause mutagenic or carcinogenic effects on aquatic life and human beings even at low concentrations [48]. Methylene blue (MB) is known to cause eye burn, irritation to the gastrointestinal tract, nausea, vomiting and diarrhoea and the quantity exceeding $5 \mathrm{mg} \mathrm{kg}^{-1}$ may precipitate serious serotonin toxicity called serotonin syndrome [49].

Various adsorbents have been applied for dye removal from aqueous solution, including activated carbon [50,51], fly ash [52,53], red mud [54], mesoporous aluminium phosphate [55], free standing carbonaceous nanofibre membranes, magnetic powder like $\mathrm{MnO}-\mathrm{Fe}_{2} \mathrm{O}_{3}$ [56] composites and porous $\mathrm{CeO}_{2}$ [57]. Various nanomaterials with well-defined morphology, such as nanoparticles, nanowires, nanobelts, nanorods, nanoflowers and nanotubes [58-61] also have been applied to remove organic dyes.

The conventional methods for waste water treatment, such as ion exchange, chemical precipitation, electro dialysis, etc. are comparatively expensive and are less user friendly than membrane processes. There is a scope for further exploring the use of newer ceramic membranes for these applications using locally available low cost materials. The present study describes preparation of ceramic membranes from easily available materials such as local PC along with different other local materials like stone quarry dust (SQD) and tea factory waste dust. The PC from this region has been traditionally used by rural artisans for the last several hundred years to prepare storage pitchers for sugarcane molasses. With the invasion of modern food packaging practices, the art and the tradition of pottery is dwindling in the area. Therefore, development of newer advanced products with the available resources may be another way to sustain the small scale industry and livelihood of the people around.

\section{Experimental}

\subsection{Chemicals and raw materials}

Locally available PC was collected from the Dhekial region of Golaghat district, Assam, India (latitude 26³6.115 min
North, longitude $93^{\circ} 58.223 \mathrm{~min}$ East, altitude $47 \mathrm{~m}$ above mean sea level) [62]. SQD was supplied by local suppliers who regularly crush stone boulders collected from Bihubor area of neighbouring Sibsagar district, Assam, India. Tea waste was collected from a local tea garden factory of Jorhat area. $\mathrm{MB}\left(\mathrm{C}_{16} \mathrm{H}_{18} \mathrm{ClN}_{3} \mathrm{~S}\right)$ and congo red (CR, $\mathrm{C}_{32} \mathrm{H}_{22} \mathrm{~N}_{6} \mathrm{Na}_{2} \mathrm{O}_{6} \mathrm{~S}_{2}$ ) were purchased from RANKEM (India) and sodium hydroxide $(\mathrm{NaOH})$ was purchased from HIMEDIA (India).

\subsection{Collection and sizing of raw materials}

All the samples were ground in a ball mill $(3 \times 4 \mathrm{HP}, 415 \mathrm{~V}$ AC, fabricated by Mineral progress equipment Pvt. Ltd., Bombay, India) containing steel balls in a ball with a sample ratio of $5: 1 \mathrm{~kg}$ per batch, mixed thoroughly by quartering and coning, sieved through 100 meshes $(149 \mu \mathrm{m})$ and stored in sample packets in dried condition for further use.

\subsection{Preparation of ceramic membranes}

Microfiltration membranes were prepared by a paste pressing method. The stepwise preparation method is shown in figure 1 . A paste of the homogeneous mixture of finely ground raw materials was prepared in a standardized ratio of the components (table 1) and cast into a disc shape using a hollow stainless steel cylinder and applying the pressure of 1 bar for 5 min using uniaxial hydraulic press to obtain a homogeneous flat green body.

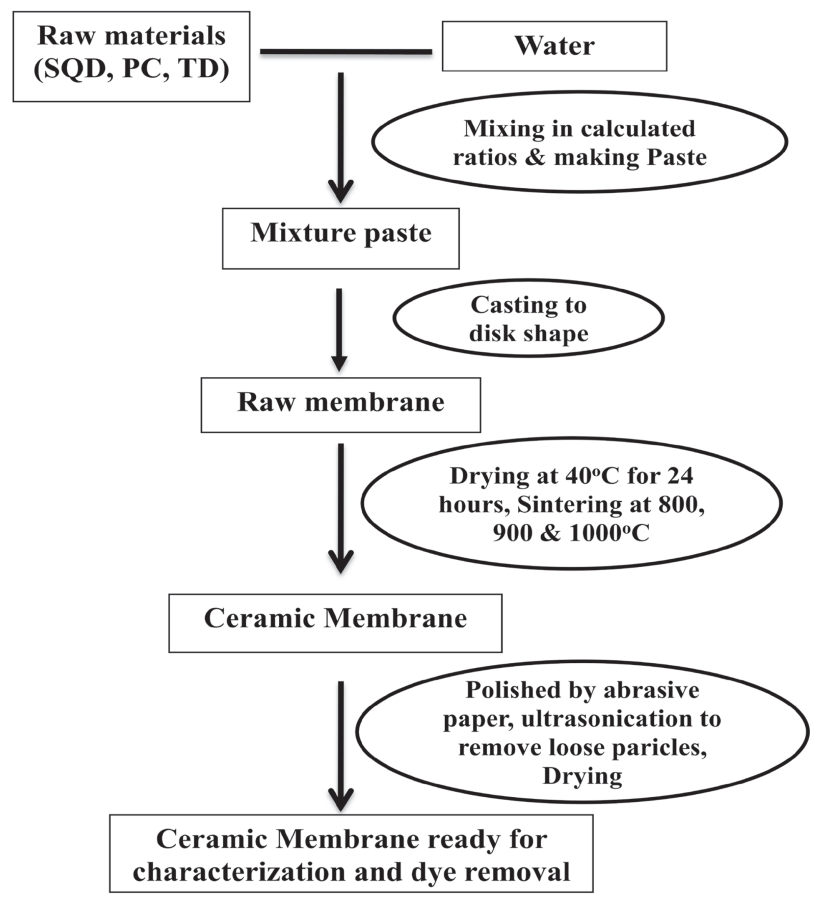

Figure 1. Schematic illustration of ceramic membrane preparation. 
Table 1. Composition of raw materials percentage of ceramic barrier.

\begin{tabular}{lcc}
\hline & \multicolumn{2}{c}{ Composition $(w t \%)$} \\
\cline { 2 - 3 } Raw materials used & Dry basis & wet basis \\
\hline PC & 25.0 & 19.23 \\
SQD & 41.67 & 32.06 \\
TD & 33.33 & 25.64 \\
Water & 0.00 & 23.07 \\
\hline
\end{tabular}

The prepared raw support was then dried at $40^{\circ} \mathrm{C}$ for $24 \mathrm{~h}$ in a hot air oven and finally fired at three different temperatures i.e., 800,900 and $1000^{\circ} \mathrm{C}$ for $6 \mathrm{~h}$ in a muffle furnace (IKON, made India model no.Ik-108, size $6^{\prime \prime} \times 6^{\prime \prime} \times 12^{\prime \prime}$, rating $4 \mathrm{~kW}$ ). Ceramic sintered membranes were polished by an abrasive paper to smoothen the surface and ultrasonicated for $10 \mathrm{~min}$ to remove loose particles. The finally obtained membrane was dried and used for characterization and dye removal experiments.

\subsection{Characterization of raw materials and ceramic membranes}

The raw materials and the ceramic membrane before and after sintering were characterized by employing different analytical methods. Classical chemical analysis of the raw materials was carried out to investigate the chemical composition of local raw materials. Particle size of the raw materials was analysed using a Malvern 7 Mastersizer 2000 instrument from an aqueous dispersion of the material. Fourier transform infrared (FTIR) analysis of the samples were carried out using FTIR (model-IR Affinity-1) by using the KBr plate method in the range of $400-4000 \mathrm{~cm}^{-1}$ at the spectral resolution of $4 \mathrm{~cm}^{-1}, 40$ scans. Thermogravimetric analysis was carried out by using a TA instrument (SDT Q 600, Ms TA Instruments, USA) using alumina as a reference at a heating rate of $20^{\circ} \mathrm{C}$ per min under an argon atmosphere from 25 to $1000^{\circ} \mathrm{C}$. X-ray diffractometry (XRD) analysis was carried out using a powder XRD instrument (model Rigaku-Ultima IV, Japan) using $\mathrm{CuK} \alpha$ radiation at the scan rate of $2^{\circ}$ per min. Field emission scanning electron micrographs (FESEM) were taken by using a FESEM apparatus from Carl Zeiss (Sigma VP). For measurement of zeta potential, a small portion of the ceramic barrier was ground in a planetary micro pulverizer (M/S Fritsch, Germany) at $600 \mathrm{rpm}$ for 2 min using zirconium balls to obtain ceramic powder of particle size in the range of $1-200 \mu \mathrm{m}$. A dispersed $0.1 \%$ aqueous solution of the ceramic powder was prepared to measure the zeta potential (Zetasizer instrument, model Nano Zs, Malvern, UK).

Physical parameters like bulk density $\left(\rho_{\mathrm{b}}\right)$, apparent density $\left(\rho_{\mathrm{a}}\right)$, apparent porosity $(\varepsilon(\%))$ and water absorption $\left(w_{\mathrm{a}}(\%)\right)$ of the porous ceramic body were evaluated using Archimedes' method with water as the wetting liquid [63].

$$
\begin{aligned}
\rho_{\mathrm{b}} & =\frac{w_{\mathrm{d}}}{w_{\mathrm{sat}}-w_{\mathrm{sus}}}, \\
\rho_{\mathrm{a}} & =\frac{w_{\mathrm{d}}}{w_{\mathrm{d}}-w_{\mathrm{sus}}}, \\
\varepsilon(\%) & =\frac{\left(w_{\mathrm{sat}}-w_{\mathrm{d}}\right)}{\left(w_{\mathrm{sat}}-w_{\mathrm{sus}}\right)} \times 100, \\
w_{\mathrm{a}}(\%) & =\frac{\left(w_{\mathrm{sat}}-w_{\mathrm{d}}\right)}{w_{\mathrm{d}}} \times 100,
\end{aligned}
$$

where $w_{\mathrm{d}}, w_{\text {sat }}$ and $w_{\text {sus }}$ are dry weight, saturated weight and suspended weight of a piece of the ceramic membrane, respectively. Ceramic membranes were dried at $110^{\circ} \mathrm{C}$ and kept in vacuum desiccators until it attained a constant weight and then the dry weight $\left(w_{\mathrm{d}}\right)$ of the specimens were noted down. Saturated weight $\left(w_{\text {sat }}\right)$ of the nodules were determined by keeping the samples in boiling water for $2 \mathrm{~h}$ and cooled to room temperature and the weight was noted down. Suspended weight $\left(w_{\text {sus }}\right)$ of the samples was determined by suspending the samples in water.

Chemical stability of the membrane towards harsh environmental conditions was evaluated by testing the stability of the membrane in acidic and basic conditions by subjecting it to concentrated $\mathrm{HCl}$ and $\mathrm{NaOH}$ solution for 20 consecutive days and results were analysed by calculating the mass losses in these conditions. The average pore diameter $\left(d_{\mathrm{s}}\right)$ of the membranes was calculated from the SEM images of the membranes of different selected areas using Image $\mathbf{J}$ software and average pore size was calculated using below equation considering cylindrical pores:

$$
d_{\mathrm{s}}=\left[\frac{\sum_{i=1}^{n} n_{i} d_{i}^{2}}{\sum_{i=1}^{n} n_{i}}\right]^{0.5},
$$

where $n$ refers to the number of pores considered and $d_{i}$ is the pore diameter $(\mathrm{nm})$ of $i$ th pore.

The pure water permeability of the membrane sintered at $900^{\circ} \mathrm{C}$ was measured using deionized water at room temperature $\left(25 \pm 2^{\circ} \mathrm{C}\right)$ conditions. The trans-membrane pressure was varied from 0 to $68.94 \mathrm{kPa}$. The permeate flux of the membrane is directly proportional to the pressure drop across the membrane in accordance with Darcy's law (equation 6):

$$
J_{\mathrm{W}}=L_{\mathrm{P}} \Delta P,
$$

where $J_{\mathrm{W}}$ is the flux, $L_{\mathrm{P}}$ the permeability and $\Delta P$ the pressure drop.

\subsection{Decolourization experiments}

A lab scale filtration unit was used for dead-end mode filtration for decolourization study as shown in figure 2. The filtration unit was made by fixing a membrane (height $=$ $0.4 \mathrm{~cm}$, diameter $=4.2 \mathrm{~cm}$ ) in a polyethylene cylindrical 

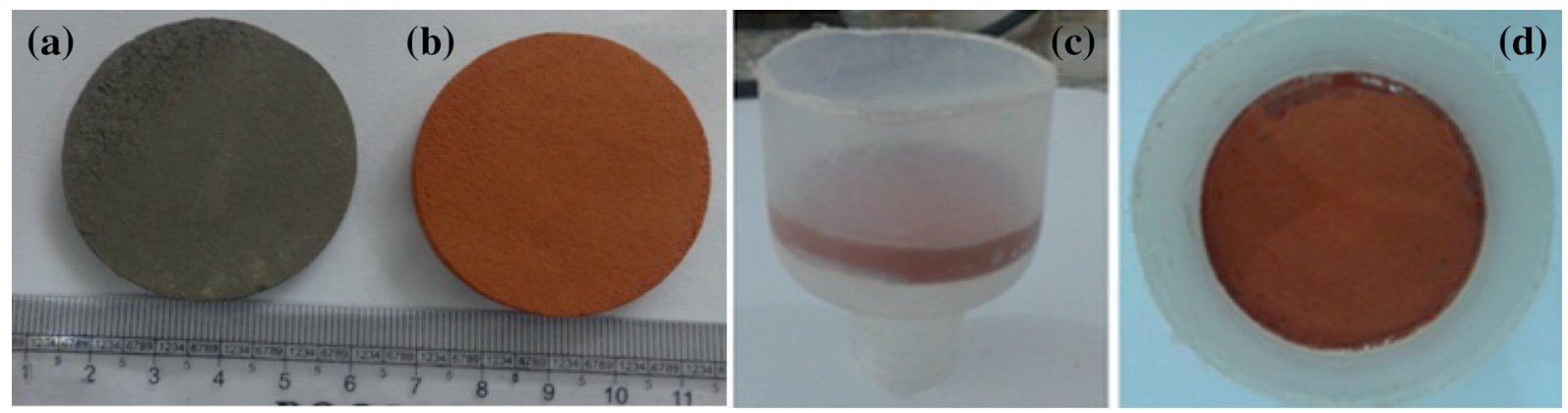

Figure 2. (a) Raw ceramic membrane, (b) ceramic membrane after sintered at $900^{\circ} \mathrm{C}$, (c) home-made filtration unit by fabricating ceramic membrane in a polypropylene container (side view) and (d) top view of the filtration unit.

Table 2. Properties and structure of the dye molecules used.

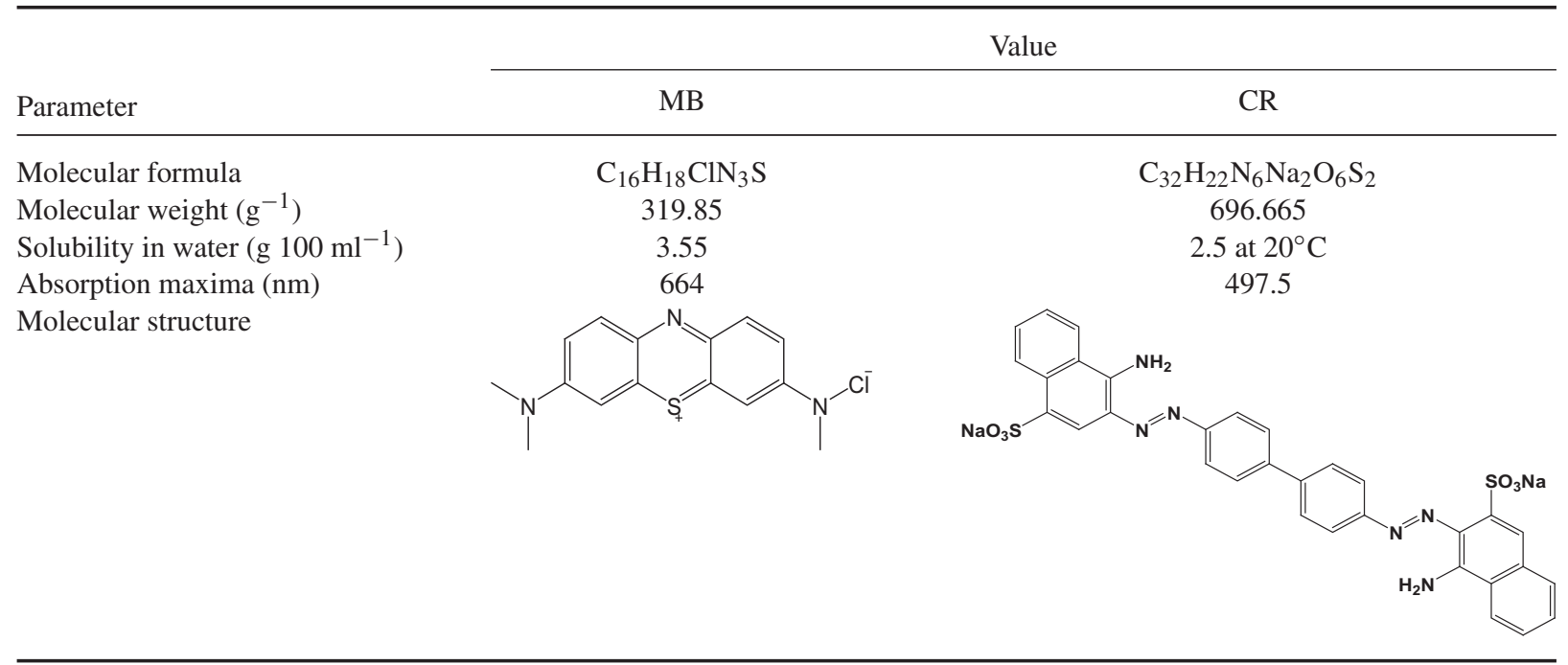

container (height $=3.7 \mathrm{~cm}$, diameter $=4.3 \mathrm{~cm}$ ) as shown in figure $2 \mathrm{c}$. $\mathrm{CR}$ and $\mathrm{MB}$ containing water was allowed to flow through the membrane simply by gravity with a flow rate of $1.6 \mathrm{ml} \mathrm{min}^{-1}$. Permeate was analysed using a UV spectrophotometer. Percent rejection $(\% R)$ was calculated by the following equation:

$$
R(\%)=\frac{\left(C_{0}-C_{\mathrm{t}}\right)}{C_{0}} \times 100
$$

where $C_{0}$ and $C_{t}$ are the initial concentrations of $\mathrm{MB}$ and $\mathrm{CR}$ at time $t$, respectively.

\subsection{Analysis of concentrations of $H B$ and CRI}

We have used $\mathrm{MB}$ and $\mathrm{CR}$ as model dyes to evaluate the efficiency of the ceramic membrane. Residual concentrations of $\mathrm{MB}$ and $\mathrm{CR}$ solutions were analysed with the help of UV-visible spectrophotometer (MS-11-UV-1800 instrument) and a series of dye solutions with concentration between 0 and $10 \mathrm{mg}^{-1}$ were used to obtain a calibration curve. The

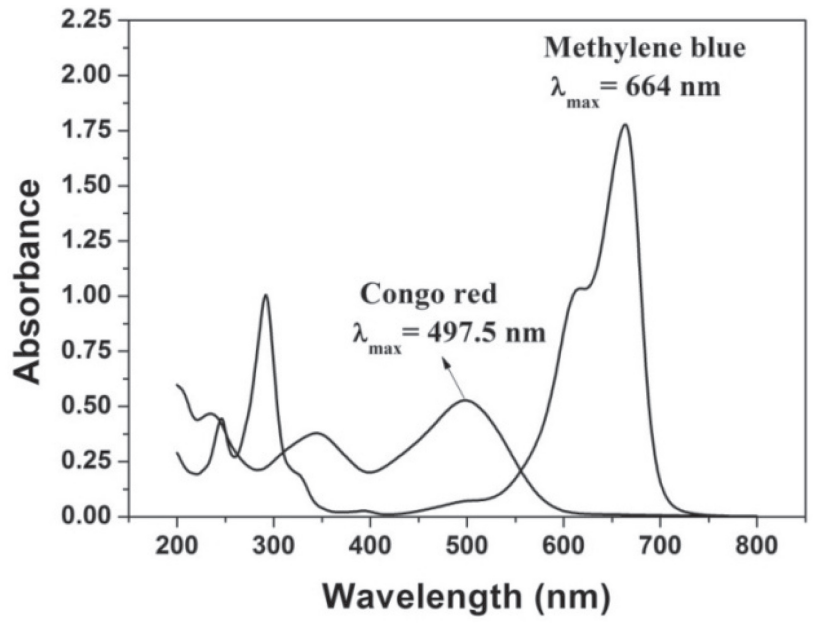

Figure 3. UV-visible spectra of $\mathrm{MB}$ and $\mathrm{CR}$ showing absorbance maxima.

calibration curves were found to be linear in this concentration range and the maximum absorption occurs at $664 \mathrm{~nm}$ for $\mathrm{MB}$ and $497.5 \mathrm{~nm}$ for CR, respectively. The 
Table 3. Chemical analysis of local materials.

\begin{tabular}{|c|c|c|c|c|c|c|c|c|c|}
\hline \multirow[b]{2}{*}{ Sample } & \multicolumn{9}{|c|}{ wt $(\%)$} \\
\hline & $\mathrm{SiO}_{2}$ & $\mathrm{Al}_{2} \mathrm{O}_{3}$ & $\mathrm{Fe}_{2} \mathrm{O}_{3}$ & $\mathrm{CaO}$ & $\mathrm{MgO}$ & $\mathrm{Na}_{2} \mathrm{O}$ & $\mathrm{K}_{2} \mathrm{O}$ & LOI* & Total \\
\hline $\mathrm{PC}$ & 55.48 & 20.78 & 7.6 & 0.45 & 0.65 & 1.01 & 1.01 & 12.63 & 99.61 \\
\hline SQD & 73.21 & 3.67 & 8.24 & 7.22 & 1.6 & 0.82 & 1.08 & 3.2 & 99.04 \\
\hline
\end{tabular}

*LOI, loss on ignition.
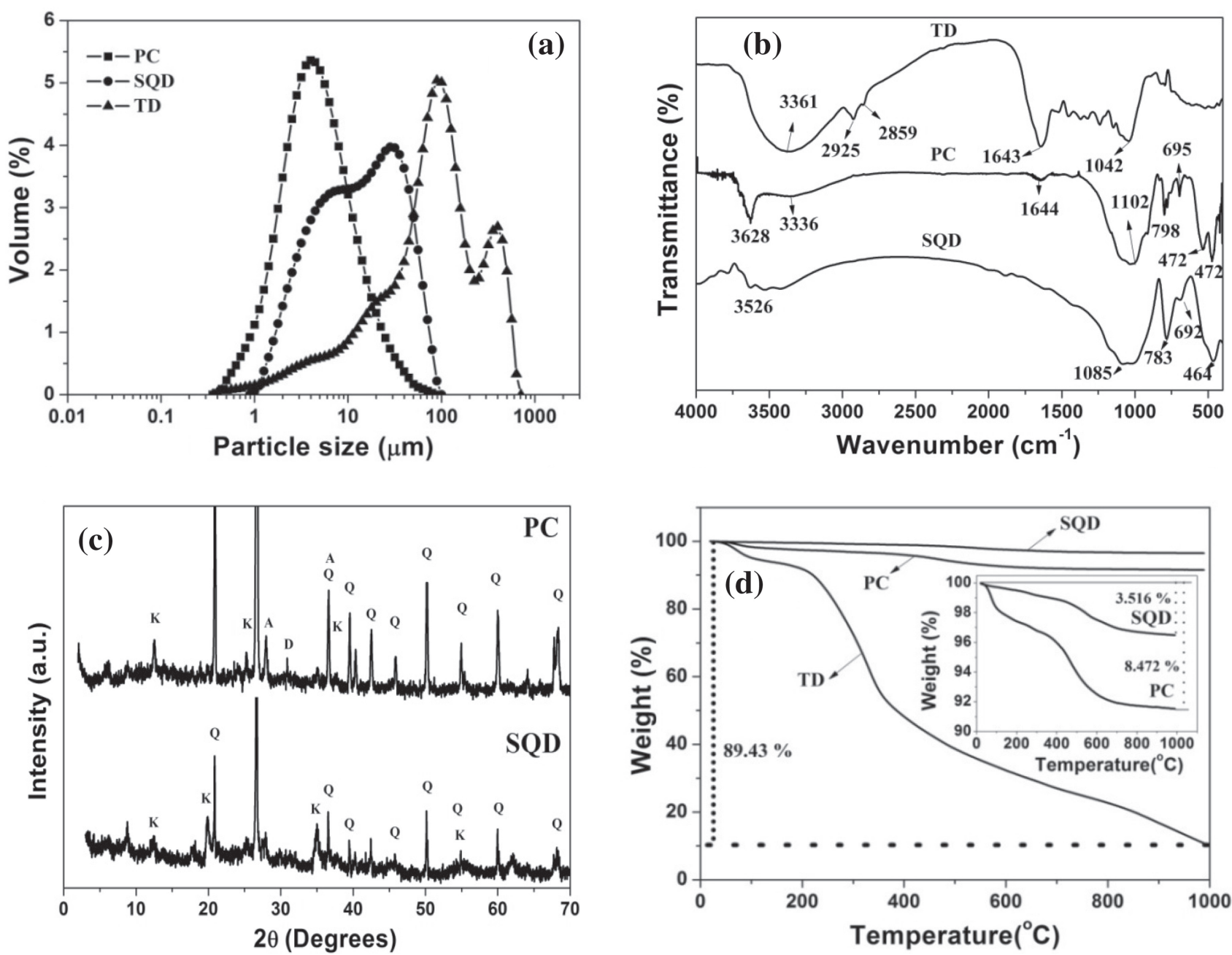

Figure 4. Characterization of raw materials: (a) particle size, (b) FTIR patterns, (c) PXRD pattern (Q, quartz; K, kaolinite; D, dolomite and A, muscovite) and (d) thermal analysis.

properties of the dye molecules and absorption maxima of $10 \mathrm{mg}^{-1}$ dye solutions are shown in table 2 and figure 3 , respectively.

\section{Results and discussion}

\subsection{Characterization of raw materials and ceramic membranes}

Oxidic chemical compositions of raw materials were calculated by classical chemical analysis of the PC and SQD as presented in table 3. Silica and iron oxide content are higher in SQD. Local PC has a comparatively low content of silica, whereas it contains a higher percentage of alumina.

Average particle size of the raw materials of the ceramic membrane is found to be $10.54 \mu \mathrm{m}$ for tea dust powder and 3.1 and $1.6 \mu \mathrm{m}$ for stone dust and local PC, respectively (figure 4a). FTIR technique was used to identify surface functional groups present in PC, SQD, TD raw and sintered ceramic membranes. The band observed at around $3628 \mathrm{~cm}^{-1}$ for local PC has been ascribed to $\mathrm{OH}$ stretching. The bands observed at around $3336 \mathrm{~cm}^{-1}$ in PC and $3526 \mathrm{~cm}^{-1}$ in SQD 

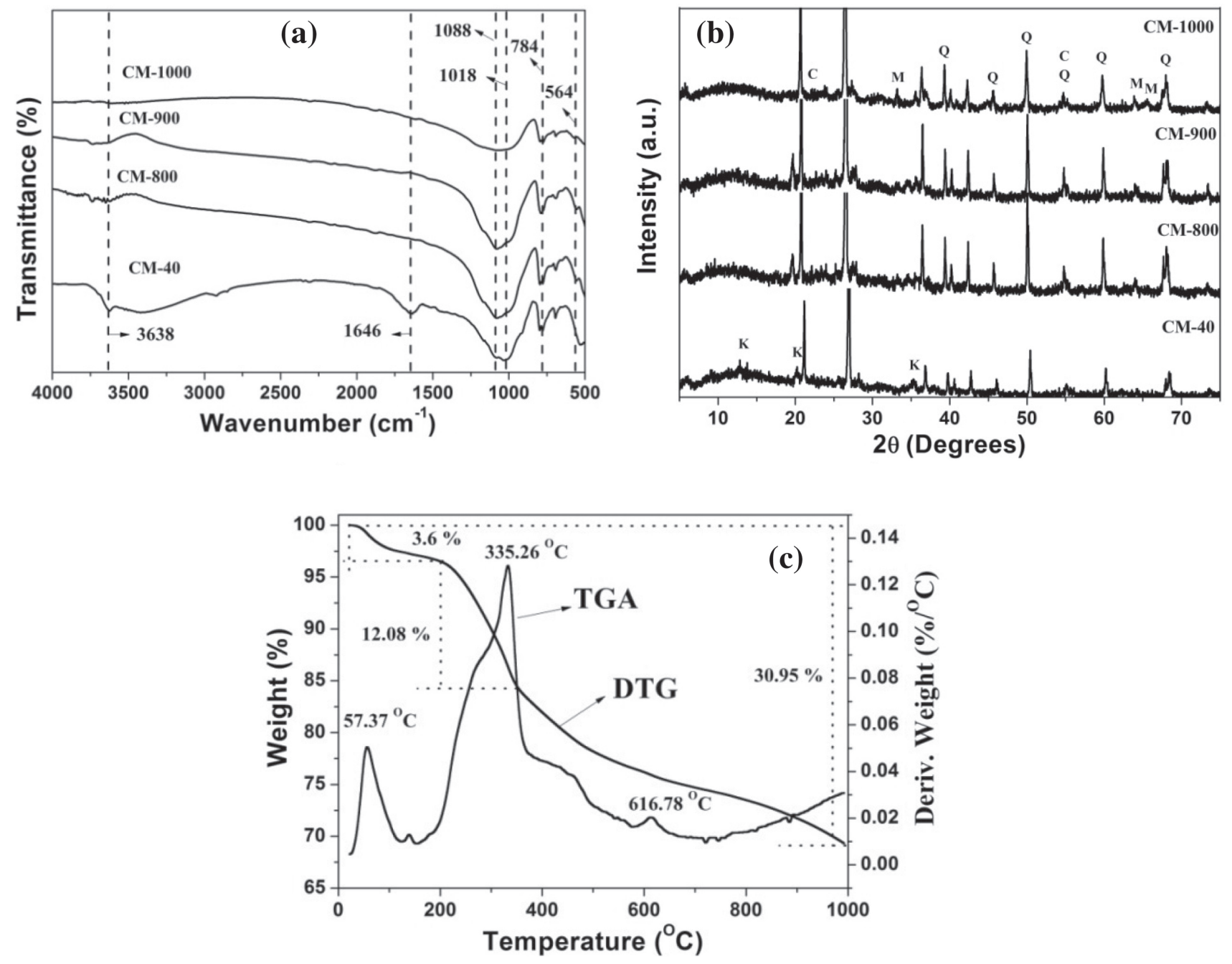

Figure 5. Overlay (a) FTIR patterns and (b) PXRD pattern (Q, quartz; K, kaolinite; C, cristobalite and M, mullite) of ceramic membranes and (c) thermal analysis of raw membrane.

can be ascribed to $\mathrm{H}-\mathrm{O}-\mathrm{H}$ stretching, crystalline hydroxyl and chemically or physically absorbed water. The $\mathrm{H}-\mathrm{O}-\mathrm{H}$ bending of water is observed at $1620-1642 \mathrm{~cm}^{-1}$. Peaks observed at around $1102 \mathrm{~cm}^{-1}$ for PC and $1085 \mathrm{~cm}^{-1}$ for SQD can be ascribed for Si-O stretching for quartz [24]. Peaks obtained at around $783-798 \mathrm{~cm}^{-1}$ can be assigned to $\mathrm{OH}$ deformation linked to $\mathrm{Al}^{3+}$ and $\mathrm{Mg}^{2+}$. The peak observed at around $457-470 \mathrm{~cm}^{-1}$ can be assigned to $\mathrm{Si}-\mathrm{O}-\mathrm{Si}$ bending. The peaks obtained from the XRD shows that the PC used is mainly composed of quartz, $\mathrm{SiO}_{2}$ (ref. code: 00-046-1045) and kaolinite, $\mathrm{Al}_{2} \mathrm{Si}_{2} \mathrm{O}_{5}(\mathrm{OH})_{4}$ (ref. code: 00-001-0527) along with small amounts of minerals like dolomite, $\mathrm{CaMg}\left(\mathrm{CO}_{3}\right)_{2}$ (ref. code: 01-071-1662) and muscovite, $\mathrm{KAl}_{2}\left(\mathrm{AlSi}_{3}\right) \mathrm{O}_{10}$ $(\mathrm{OH}, \mathrm{F})_{2}$ (ref. code: 00-002-0467). In the SQD sample, quartz is the main composition along with a small amount of kaolinite.

The XRD analysis of the green membrane and the burnt ceramic membrane at $1000^{\circ} \mathrm{C}$ to investigate the phases formed during the firing process is shown in figure $5 \mathrm{~b}$. From the
$\mathrm{XRD}$ pattern, in the sintered barrier at $1000^{\circ} \mathrm{C}$, quartz is the main mineral obtained along with new peaks assigned as mullite, $3 \mathrm{Al}_{2} \mathrm{O}_{3} \cdot 2 \mathrm{SiO}_{2}$ (ref. code: 00-002-0452) and cristobalite, $\mathrm{SiO}_{2}$ (ref. code: 00-001-0424) in small proportions. It is seen that the intensity of the quartz peak with the (101) plane increases by the increase in firing temperature up to $900^{\circ} \mathrm{C}$ and slowly decreases at $1000^{\circ} \mathrm{C}$ due to the formation of other minerals like mullite and cristobalite at high temperature. Thermal analysis of individual components of ceramic membranes (figure 5c) was carried out to study the thermal stability and \% weight loss. PC and SQD showed a weight loss of 8.47 and $3.52 \%$, respectively. Individual components were found to be quite stable at $900^{\circ} \mathrm{C}$, which is the sintering temperature of the ceramic membranes.

Thermal analysis shows that ceramic membranes are quite stable at high temperatures. In green composites, two main transitions were observed at around 40 and $360^{\circ} \mathrm{C}$ with a total weight loss of $30.7 \%$. The higher weight loss obtained is due 

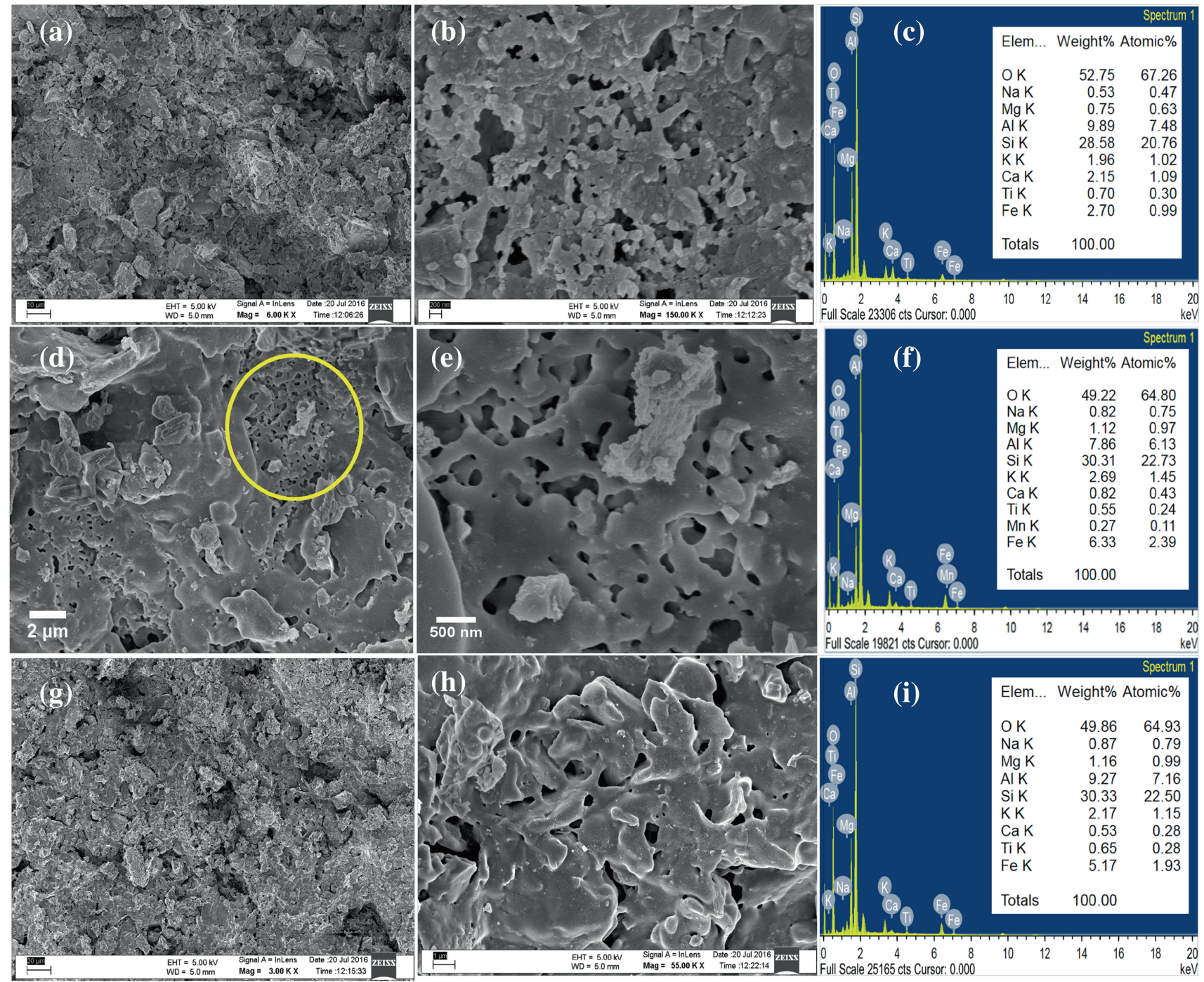

Figure 6. FESEM and EDS analysis of ceramic membrane fired, $(\mathbf{a}, \mathbf{b}, \mathbf{c})$ at $800^{\circ} \mathrm{C},(\mathbf{d}, \mathbf{e}, \mathbf{f})$ at $900^{\circ} \mathrm{C}$ and $(\mathbf{g}, \mathbf{h}, \mathbf{i})$ at $1000^{\circ} \mathrm{C}$.

to the addition of tea dust materials as pore-forming agent. The clay used is a kaolinite type of clay. A collapse of kaolinite network is reported in the temperature range of $450-600^{\circ} \mathrm{C}$. Removal of water transforms kaolinite to metakaolin in which the $\mathrm{Si}-\mathrm{O}$ network remains unchanged and the $\mathrm{Al}-\mathrm{O}$ network reconstructs itself as shown in equation (8). A further increase in the sintering temperature above $900^{\circ} \mathrm{C}$ results in the decomposition of the metakaolinite to mullite and cristobalite [64].

$$
\begin{aligned}
& \mathrm{Si}_{2} \mathrm{O}_{5} \mathrm{Al}_{2}(\mathrm{OH})_{4} \stackrel{450-650^{\circ} \mathrm{C}}{\longrightarrow} 2 \mathrm{SiO}_{2}, \mathrm{Al}_{2} \mathrm{O}_{3}+2 \mathrm{H}_{2} \mathrm{O}, \\
& 2\left(\mathrm{SiO}_{2}, \mathrm{Al}_{2} \mathrm{O}_{3}\right) \stackrel{900-1000^{\circ} \mathrm{C}}{\longrightarrow} \mathrm{SiO}_{2}+3 \mathrm{SiO}_{2}, 2 \mathrm{Al}_{2} \mathrm{O}_{3} .
\end{aligned}
$$

Electron microscopy analysis was carried out to analyse the possible surface defects and to confirm the pore generation in the membrane surface. FESEM monographs of sintered ceramic membranes (figure 6) shows that the surface
Table 4. Different physical properties of ceramic barriers with

\begin{tabular}{|c|c|c|c|}
\hline \multirow[b]{2}{*}{ Parameters } & \multicolumn{3}{|c|}{ Type of membrane } \\
\hline & CM-800 & CM-900 & CM-1000 \\
\hline Firing temperature, ${ }^{\circ} \mathrm{C}$ & 800 & 900 & 1000 \\
\hline Water absorption, $\%$ & 57.86 & 47.43 & 21.62 \\
\hline Apparent density, $\mathrm{g} \mathrm{cm}^{-3}$ & 2.21 & 2.33 & 2.23 \\
\hline Bulk density, $\mathrm{g} \mathrm{cm}^{-3}$ & 0.97 & 1.11 & 1.5 \\
\hline Apparent porosity, $\%$ & 56.1 & 52.51 & 32.58 \\
\hline
\end{tabular}
different compositions.

is critically rough and highly porous with non-uniform pore distribution. On increasing the sintering temperature from 800 to $1000^{\circ} \mathrm{C}$, the pores are observed to reduce as the grains are fused and minerals melt at higher temperature as seen in figure $6 \mathrm{~g}$ and $\mathrm{h}$, where the exposed surface of the membrane 

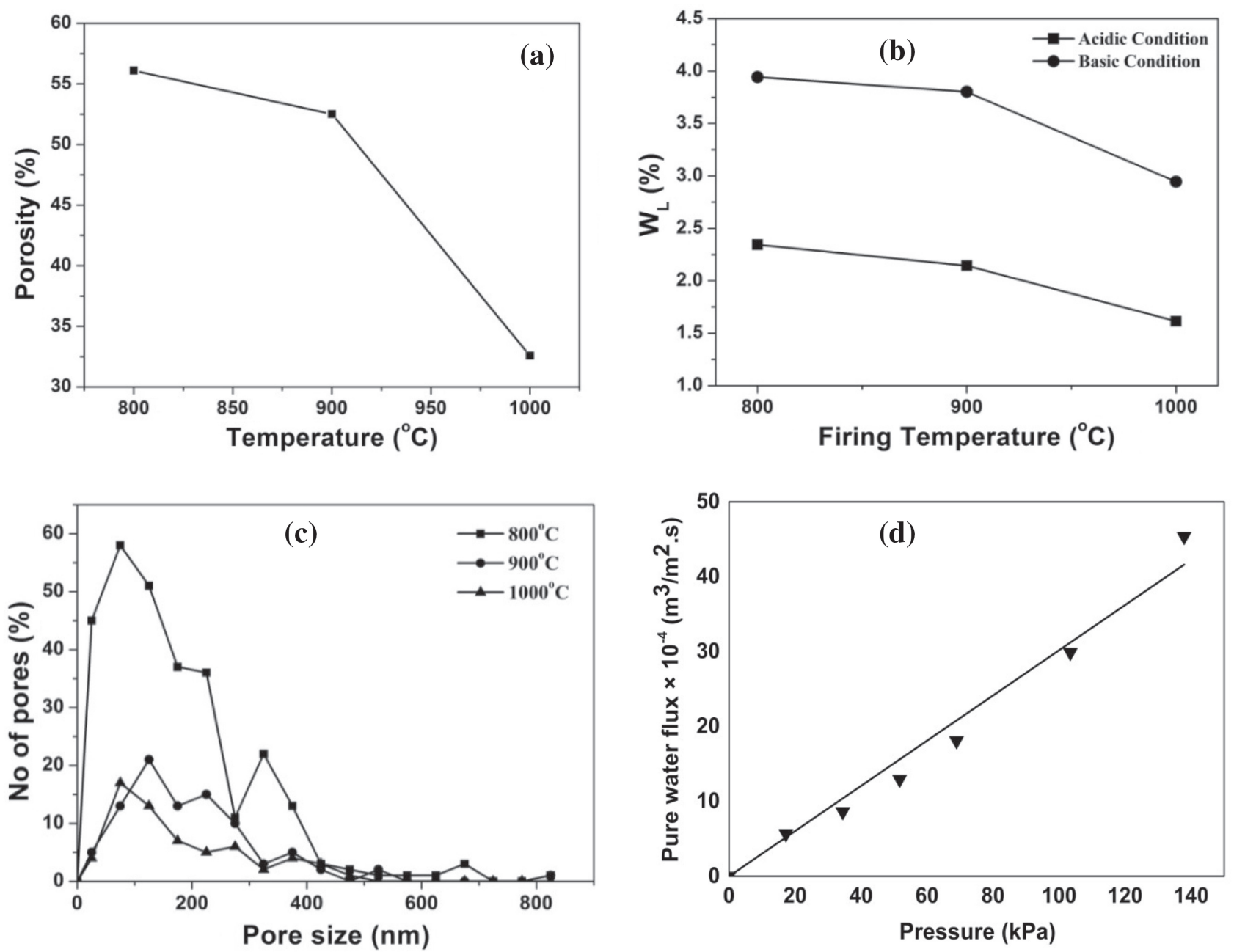

Figure 7. Effect of sintering temperature on (a) porosity \%, (b) chemical stability, (c) pore size distribution of the ceramic membrane and (d) pure water permeability of the ceramic membrane sintered at $900^{\circ} \mathrm{C}$.

fired at $1000^{\circ} \mathrm{C}$ appears melted and pores were blocked. It is clear from table 4 that porosity decreases from 56.1 to $52.5 \%$ on increasing firing temperature from 800 to $900^{\circ} \mathrm{C}$ and decreased to $32.58 \%$ on further increasing the sintering temperature up to $1000^{\circ} \mathrm{C}$ which is explained that due to the melting of minerals at a higher temperature resulting in the pore blocking (figure 7a).

As water absorption is directly related to porosity $\%$, the same trend was observed on increasing the firing temperature also. Figure $7 \mathrm{~d}$ shows that the pure water permeability of the membrane sintered at $900^{\circ} \mathrm{C}$, increases linearly with an increase in the applied pressure i.e., it follows the Darcy's law. The average pore size of membranes sintered at different temperatures are determined as $0.215,0.49$ and $0.211 \mu \mathrm{m}$ for sintering temperatures of 800,900 and $1000^{\circ} \mathrm{C}$, respectively. Pore size distribution of the membranes corresponds to microfiltration range of ceramic membrane. Pore size distribution is observed to be closely related to the sintering temperature and found to increase initially on increasing the temperature from 800 to $900^{\circ} \mathrm{C}$, but on further increase

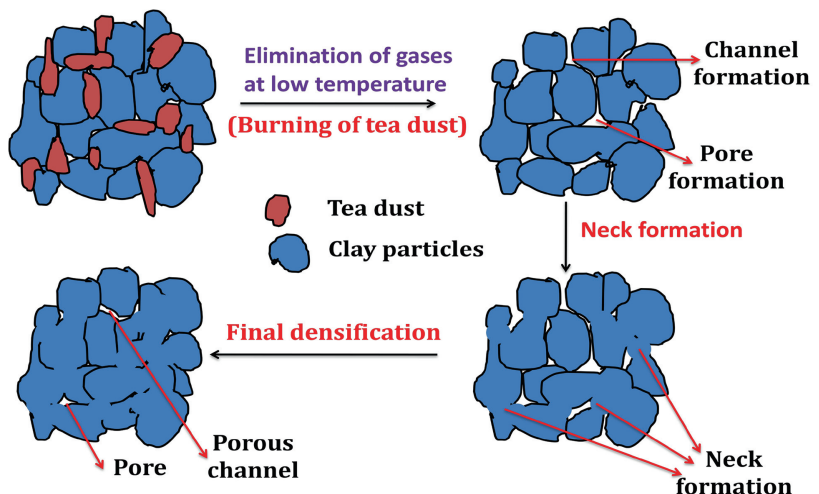

Figure 8. Schematic representation of ceramic membrane formation mechanism.

to $1000^{\circ} \mathrm{C}$, the pore size decreases, which is possibly due to the melting of minerals at higher temperatures causing reduction of the pore size and overall porosity of the membrane. 

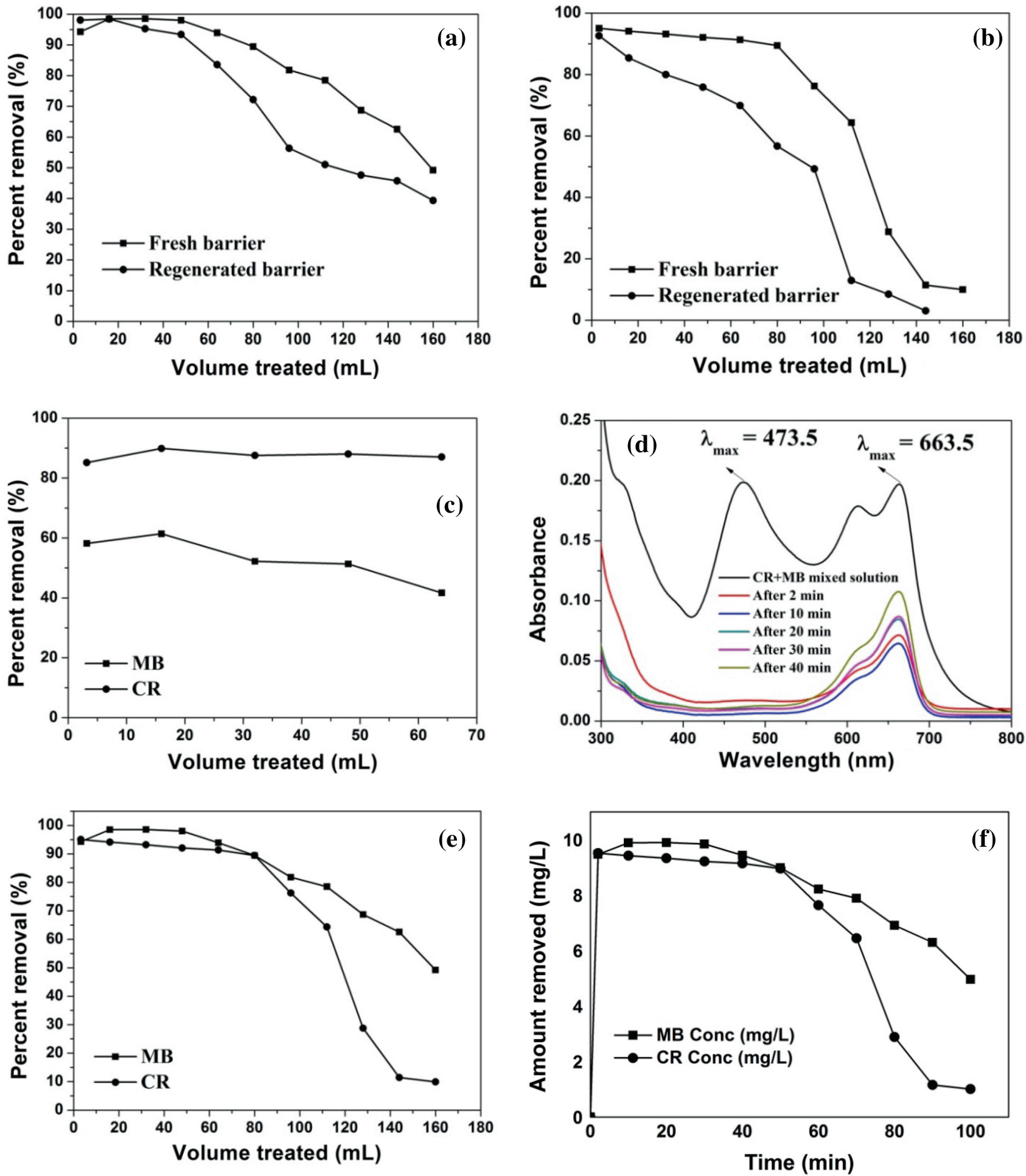

Figure 9. Dye removal of (a) MB, (b) CR by CM-900 and regenerated membrane, (c) simultaneous removal of CR and MB, (d) UVVisible spectra showing variations in absorbance of $\mathrm{CR}$ and $\mathrm{MB}$ solutions with time after simultaneous removal by the barrier from 2 to 40 min, (e) comparison of MB and CR removal by the barrier and (f) amount of MB and CR removal by the barrier.

As density of the material is inversely related to the pore volume, bulk density and apparent density were observed to increase on increasing the firing temperature. Chemical stability of the sintered membranes was checked in terms of weight loss in contact with acids or bases. A small part of the ceramic membrane was kept in acidic conditions in contact 

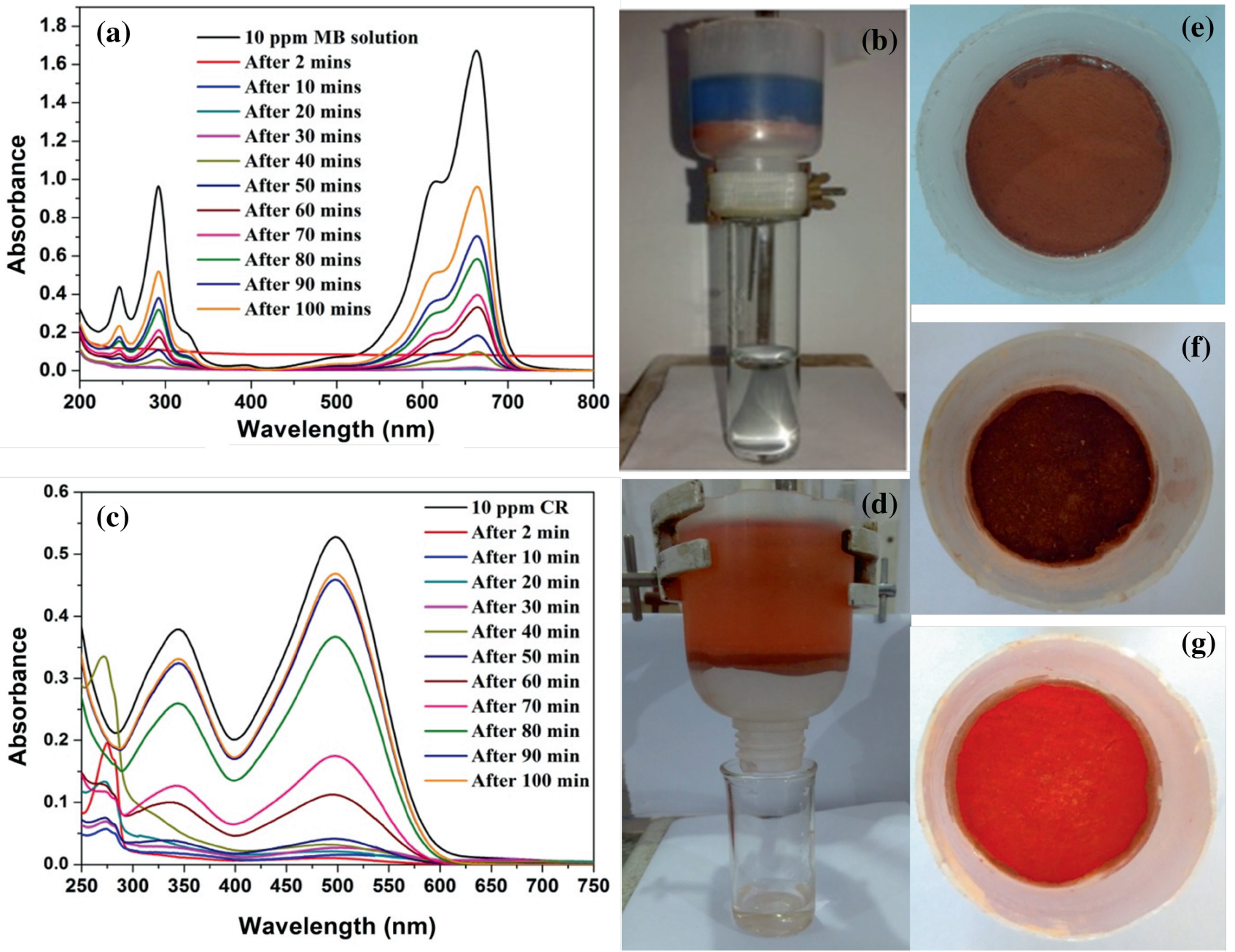

Figure 10. Continuous mode decolourization set up (a) for $\mathrm{MB}$, (b) for $\mathrm{CR}$, absorbance spectra with time for the removal of (c) $\mathrm{MB}$, (d) CR and colour change of the barrier (e) before and after (f) MB and (g) CR dye separation.

with $\mathrm{HCl}(\mathrm{pH}=2)$ and in alkali $\mathrm{NaOH}$ solution $(\mathrm{pH}=10)$ individually for 20 consecutive days at room conditions and the net weight loss was calculated after drying.

The stability in terms of weight loss of the membrane as a function of firing temperature towards acidic and basic conditions followed the order of $800<900<1000^{\circ} \mathrm{C}$. Stability towards acidic condition is found to be higher as compared to the basic condition (figure 7b). Stability of the membrane at high sintering temperature is due to the shrinking of grains at higher temperature and evaporation of acid and base leachable compounds at higher temperature.

The mechanism of growth of the ceramic membrane involves many stages in the sintering process (figure 8). The initial stage involves the burning of porogenic particles (tea dust) in the temperature range $200-500^{\circ} \mathrm{C}$ resulting in the formation of pores and channels in the membrane. The second stage is shown as the formation of neck structures of clay particles at high temperature which is very common in ceramic sintering process and also observed in the FESEM
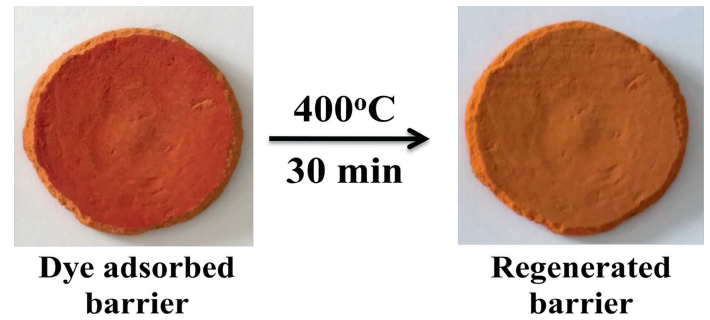

Figure 11. Regeneration of ceramic membrane by calcining at $400^{\circ} \mathrm{C}$ for $30 \mathrm{~min}$.

images. This stage reduces the pores generated during the first stage. Finally, densification of the ceramic mass occurs at higher temperatures. For clay-based membranes, this step is achieved at a lower sintering temperature as compared to the metal oxide-based membranes. Further sintering decreases the pores due to melting and fusion of the mineral particles. 
Table 5. Raw materials cost analysis study of ceramic membranes (in Indian rupees, Rs.).

\begin{tabular}{lcccc}
\hline Raw materials & $\begin{array}{c}\text { Unit price } \\
\text { (Rs. per kg) }\end{array}$ & $\begin{array}{l}\text { Raw material used (g) } \\
\text { per m } \text { of membrane }^{2}\end{array}$ & $\begin{array}{c}\text { Raw material cost } \\
\text { per m } \text { of membrane (Rs.) }^{2}\end{array}$ & $\begin{array}{c}\text { Cost per } \mathrm{m}^{2} \text { of } \\
\text { membrane }(\text { Rs. })\end{array}$ \\
\hline PC & 0.5 & 2166.157 & 1.083 & 42.46 \\
SQD & 0.79 & 3610.785 & 2.816 \\
Tea dust (TD) & 10.00 & 2888.628 & 28.814 \\
Distilled water & 5.00 & 1949.824 & 9.749 \\
\hline
\end{tabular}

\subsection{Dye removal study}

The efficacy of the adsorbent was studied in batch mode by using a home-made lab scale filtration unit in fixed bed condition. For this study, $10 \mathrm{mg} \mathrm{l}^{-1} \mathrm{CR}$ and $\mathrm{MB}$ aqueous solutions were prepared and the removal capacity of the barrier with respect to volume treated was analysed. Percentage removal (figure 9) was plotted with volume treated to compare the efficiency of fresh and regenerated membranes. The absorbance spectra of CR and MB with time are shown in figure 10 with the full setup of the decolourization experiments. It is clear that in the case of MB, remov efficiency is quite good when checked up to $100 \mathrm{~min}$ with a flow rate of $1.6 \mathrm{ml} \mathrm{min}^{-1}$ and $98.53 \%$ was removed in $20 \mathrm{~min}$. Then, it decreases slowly to $49.22 \%$ in $100 \mathrm{~min}$. Figure $9 \mathrm{f}$ shows the removal of amount of dye with time. Dye removal is quite good in the initial stages and around $95 \%$ was removed up to 40 min which decreases on further treatment due to the occupation of the adsorption sites. In the case of MB, removal capacity decreased up to $50 \%$ after $100 \mathrm{~min}$, whereas the removal capacity of the barrier for $\mathrm{CR}$ is poor in comparison with MB. Although it showed initially good removal efficiency, it became almost saturated in $100 \mathrm{~min}$ and the removal capacity decreased to $10 \%$.

Regeneration of the used ceramic membrane is possible by calcining at low temperature [65]. The regeneration was carried out by calcining the exhausted membrane at $400^{\circ} \mathrm{C}$ for $30 \mathrm{~min}$ in air (figure 11) and used further for another cycle of dye separation. The regenerated barrier is also capable of separation of dye molecules from water with a good efficiency with $>98 \%$ initial removal, but gets saturated gradually and the final removal capacity decreased to $39.3 \%$ in $100 \mathrm{~min}$ after treatment with $160 \mathrm{ml}$ of $10 \mathrm{mg} \mathrm{l}^{-1} \mathrm{MB}$ solutions (figure 9a and b). However, in comparison with fresh barriers, regenerated barrier showed less efficiency towards dye adsorption. Initially, the separation capacity is almost similar, but after treatment of $40 \mathrm{ml} \mathrm{MB}$ solution, the removal capacity decreased by around $15 \%$ as compared to the fresh barrier and a continual decrease in removal efficiency is observed from the beginning in the case of CR removal by the regenerated barrier. The decrease in efficiency of removal between fresh and regenerated barriers remained constant and showed almost $15 \%$ decrease. This decrease in removal percentage on regeneration may be ascribed to localized heating during burning of residual dye molecules present in the pores of the barriers.

Efficiency of the membrane for simultaneous removal of $\mathrm{CR}$ and $\mathrm{MB}$ was studied by preparing a mixed solution containing $3.96 \mathrm{mg} \mathrm{l}^{-1} \mathrm{CR}$ and $1.12 \mathrm{mg} \mathrm{l}^{-1} \mathrm{MB}$. On mixing the two dyes, the maximum absorption peaks changed considerably in the case of CR from 497.5 to $473.5 \mathrm{~nm}$ due to the change in $\mathrm{pH}$, whereas in the case of $\mathrm{MB}$, no such major change is observed. It is observed that $\mathrm{CR}$ removal was quite good, but in the presence of CR, adsorption of MB is comparatively poor, which is only about $60 \%$ from $1.12 \mathrm{mg} \mathrm{l}^{-1}$ solution (figure 9c), whereas on its own, it can remove around 99.99\% in the absence of CR.

To understand whether removal is by adsorption or by microfiltration, a barrier was kept submerged in a $10 \mathrm{mg}^{-1}$ $\mathrm{CR}$ and MB solution for 1 and 7 days. Only very small amount was adsorbed but on filtering through the barrier, $99.9 \%$ is removed immediately. From this study, it can be said that removal is a combination effort of both adsorption and microfiltration. This is also supported by the colour change of the barrier after dye separation (figure 10). From the zeta potential study of the ceramic barrier, the negative surface charge of $-18.78 \mathrm{mV}$ observed which is basically common for claybased barrier and is responsible for the adsorption of the cationic dyes more easily as compared to the anionic dyes.

\subsection{Cost analysis based on raw material}

It is important to analyse the cost of any process to determine its practical feasibility. In this work, we have calculated the cost of raw materials used for the preparation of ceramic membranes. The cost of raw materials for preparing ceramic membrane was evaluated to be Rs. 42.46 per $\mathrm{m}^{2}$ of membrane (US $\$ 0.65$ per $\mathrm{m}^{2}$ of membrane; table 5). Hence, from the cost analysis, it can be concluded that the raw material cost of ceramic membranes is inexpensive and can easily be prepared and used for dye removal purposes.

\section{Conclusions}

Ceramic membranes have been successfully prepared and characterized from locally available PC, SQD and tea waste 
materials that have negligible commercial value. The membrane obtained by the powder pressing method has a smooth surface, eventual generation of pores and showed very good thermal, chemical and mechanical stabilities. Sintering temperature was varied from 800 to $1000^{\circ} \mathrm{C}$ and it was observed that at $900^{\circ} \mathrm{C}$ a very good product with stability towards chemical corrosion, good mechanical strength and porosity is obtained. Thus, $900^{\circ} \mathrm{C}$ temperature was fixed as optimized sintering temperature. Decolourization experiments were carried out in continuous mode by a home-made fabricated filter unit which showed very good removal of CR and MB up to $99.92 \%$ reduction. Regeneration of the membrane with good efficiency is possible by calcining at $400^{\circ} \mathrm{C}$ for $30 \mathrm{~min}$. However, from the reusability point of view, the membrane showed better performance for removal of MB than CR which can be explained as the clay-based membrane surface is generally negatively charged and adsorption of cationic dyes and molecules are more favoured. The raw material cost was found to be quite cheap, which is only about Rs. 42.46 per $\mathrm{m}^{2}$ of membrane (US\$ 0.65 per $\mathrm{m}^{2}$ of membrane). The membrane being very cheap could be highly promising for future wastewater treatment applications.

\section{Acknowledgements}

We are thankful to the Director, CSIR-NEIST, Jorhat, India, for his kind permission to publish this work and to Department of Science and Technology (DST), New Delhi (GPP-296), for financial support, project no. CSC-0408 for FESEM facility and AcSIR, India, for giving the opportunity for $\mathrm{PhD}$ registration.

\section{References}

[1] Jedidi I, Khemakhem S, Larbot A and Amar R B 2009 Ceram. Int. 352747

[2] Khemakhem S, Larbot A and Amar R B 2009 Ceram. Int. 35 55

[3] Baraka N E, Saffaj N, Mamouni R, Laknifli A, Younssi S A, Albizane A et al 2014 Desalin. Water Treat. 521357

[4] Li L, Chen M, Dong Y, Dong X, Cerneaux S, Hampshire S et al 2016 J. Eur. Ceram. Soc. 362057

[5] Das B, Chakrabarty B and Barkakati P 2016 Ceram. Int. 42 14326

[6] Benfer S, Arki P and Tomandl G 2004 Adv. Eng. Mater. 6495

[7] Sudilovskiy P S, Kagramanov G G, Trushin A M and Kolesnikov V A 2007 Clean Technol. Environ. Policy 9189

[8] Parma S and Chowdhury P 2014 IJRET 3725

[9] Sharmiwati M S, Mizan R M and Noorhelinahani A B 2014 IJSTR 3103

[10] Hristov P, Yoleva A, Djambazov S, Chukovska I and Dimitrov D 2012 J. Univ. Chem. Technol. Metall. 47476

[11] Mert B K and Kestioglu K 2014 Clean Technol. Environ. Policy 161615
[12] Acharya N K 2017 Bull. Mater. Sci. 40537

[13] Akbarnezhad S, Mousavi S M and Sarhaddi R 2010 Indian J. Sci. Technol. 31048

[14] Nandi B K, Das B, Uppaluri R and Purkait M K 2009 J. Food Eng. 95597

[15] Hildebrand C, Kuglin V B, Brandao H L, Vilar V J P, Ulson G, de Souza S M A et al 2014 Clean Technol. Environ. Policy 16 591

[16] Qiu W Z, Yang H C, Wan L S and Xu Z K 2015 J. Mater. Chem. A 314438

[17] Ghosh U K, Pradhan N C and Adhikari B 2006 Bull. Mater. Sci. 29225

[18] Sokolowski K, Fraczek-Szczypta A, Tomala J and Blazewicz S 2018 Korean J. Chem. Eng. 351354

[19] Guizard C, Ayral A and Julbe A 2002 Desalination 147275

[20] Friend K A D, Wiesner M R and Barron A R 2003 J. Membr. Sci. 22411

[21] Gestel T V, Vandecasteele C, Buekenhoudt A, Dotremont C, Luyten J, Leysen R et al 2002 J. Membr. Sci. 20773

[22] Falamaki C, Shafiee A M and Aghaie A 2004 J. Eur. Ceram. Soc. 242285

[23] Wang Y H, Tian T F, Liu X Q and Meng G Y 2006 J. Membr. Sci. 280261

[24] Yoshino Y, Suzuki T, Nair B N, Taguchi H and Itoh N 2005 J. Membr. Sci. 2678

[25] Singh P S, Chaudhri S G, Kansara A M, Schwieger W, Selvam T, Reuss S et al 2015 Bull. Mater. Sci. 38565

[26] Doke S M and Yadav G D 2016 Clean Technol. Environ. Policy 18139

[27] Chen N, Feng C, Yang J, Gao Y, Li M and Zhang B 2013 Clean Technol. Environ. Policy 15375

[28] Morris R E, Krikanova E and Shadman F 2004 Clean Technol. Environ. Policy 696

[29] Potdar A, Sukla A and Kumar A 2002 J. Membr. Sci. 210 209

[30] Belouatek A, Benderdouche N, Addou A, Ouagued A and Bettahar N 2005 Microporous Mesoporous Mater. 85163

[31] Lorente-Ayza M M, Mestre S, Menendez M and Sanchez E 2015 J. Eur. Ceram. Soc. 353681

[32] Masmoudia S, Larbot A, Fekia HE and Amar R B 2006 Desalination 19089

[33] Belibi P B, Nguemtchouin M M G, Rivallin M, Nsami J N, Sieliechi J, Cerneaux S et al 2015 Ceram. Int. 412752

[34] Liu J, Dong Y, Dong X, Hampshire S, Zhu L, Zhu Z et al 2016 J. Eur. Ceram. Soc. 361059

[35] Jana S, Purkait M K and Mohanty K 2010 Appl. Clay Sci. 47 317

[36] Majouli A, Younssi S A, Tahiri S, Albizane A, Loukili H and Belhaj M 2011 Desalination 27761

[37] Chen X, Yong S, Yeo E, Woo J Y I, Zhou Y and Hong L 2017 J. Eur. Ceram. Soc. 373443

[38] Kouras N, Harabi A, Bouzerara F, Foughali L, Policicchio A, Stelitano S et al 2017 J. Eur. Ceram. Soc. 373159

[39] Achiou B, Elomari H, Ouammou M, Albizane A, Bennazha J, Younssi S A et al 2016 J. Mater. Environ. Sci. 7196

[40] Foorginezhad S and Zerafat M M 2017 Ceram. Int. 4315146

[41] Rawat M and Bulasara V K 2018 Korean J. Chem. Eng. 35725

[42] Jafry H R, Liga M V, Li Q and Barron A R 2010 New J. Chem. 35400

[43] Scalese S, Nicotera I, D'Angelo D, Filice S, Libertino S, Simari C et al 2016 New J. Chem. 403654 
[44] Buan A C J, Lynn A, Soliven A D, Cao E P, Barraquio V L and Barraquio W L 2010 Philipp. J. Sci. 13971

[45] Abinayasri P, Nageswari M, Meenarathi B and Anbarasan R 2017 Bull. Mater. Sci. 40591

[46] Xia S, Zhang L, Pan G, Qian P and Ni Z 2015 Phys. Chem. Chem. Phys. 175345

[47] Zhao D H, Zhang Y L, Wei Y P and Gao H W 2009 J. Mater. Chem. 197239

[48] Valmurugan P, Kumar V R and Dhinakaran G 2011 IJES 1976

[49] Gillman P K 2006 Anaesthesia 611007

[50] Pathania D, Sharma S and Singh P 2017 Arab J. Chem. 10 S1445

[51] Amalraj A and Pius A 2014 Sep. Sci. Technol. 4990

[52] Patra G, Barnwal R, Behera S K and Meikap B C 2018 J. Environ. Chem. Eng. 65204

[53] Mohan D, Singh K P, Singh G and Kumar K 2002 Ind. Eng. Chem. Res. $\mathbf{4 1} 3688$

[54] Bhatnagar A, Vilar V J P, Botelho C M S and Boaventura R A R 2011 Environ. Technol. 32231

[55] Kannan C, Muthuraja K and Devi M R 2013 J. Hazard. Mater. 244-245 10
[56] Wu R, Qua J and Chen Y 2005 Water Res. 39630

[57] Ouyang X, Li W, Xie S, Zhai T, Yu M, Gan J et al 2013 New J. Chem. 37585

[58] Tan K B, Vakili M, Horri B A, Poh P E, Abdullah A Z and Salamatinia B 2015 Sep. Purif. Technol. 150229

[59] Mahmoud H R, Ibrahim S M and El-Molla S A 2016 Adv. Powder Technol. 27223

[60] Anastopoulos I, Hosseini-Bandegharaei A, Fu J C A, Mitropoulos A C and Kyzas G Z 2018 J. Disper. Sci. Technol. 39 836

[61] Chawla S, Uppal H, Yadav M, Bahadur N and Singh N 2017 Ecotoxicol. Environ. Saf. 13568

[62] Saikia J, Sarmah S, Ahmed T H, Kalita P J and Goswamee R L 2017 J. Environ. Chem. Eng. 52488

[63] Manohar 2012 IJMER 21492

[64] Mouiya M, Abourriche A, Bouazizi A, Benhammou A, Hafiane Y E, Abouliatim Y et al 2018 Desalination 427 42

[65] Tolba G M K, Bastaweesy A M, Ashour E A, Abdelmoez W, Khalil K A and Barakat N A M 2016 Arab J. Chem. 9 287 